\title{
Feature Based watermarking algorithm for Image Authentication using D4 Wavelet Transform
}

\author{
Kartik Sau ${ }^{1}$ Amitabha Chanda ${ }^{2}$ Milan $\mathrm{Pal}^{3}$ \\ ${ }^{1}$ Department of Computer Science \& Engineering, Budge Budge Institute of technology, \\ BBIT Nischintapur. Kolkata 7000137, WBUT, India. \\ e-mail: kartik_sau2001@yahoo.co.in \\ ${ }^{2}$ Department of Computer Science \& Engineering, Guest faculty, UCSTA, University of \\ Calcutta, India. \\ e-mail: amitabha39@yahoo.co.in \\ ${ }^{3}$ Department of Computer science \& Engineering, Institute of engineering and \\ Management, Salt Lake, WBUT, Kolkata -700091, India. \\ e-mail:milanpal2005@gmail.com
}

\begin{abstract}
:
In this paper we propose a new watermarking schema i.e. the combination of color space and wavelet transform. Watermarking is a technique that authenticates a digital picture by hiding the secret information into the image. Now, a lot of algorithms and methods have been developed for greyscale images but the particularities of color spaces have to be studied. On the other hand, the wavelet transform allows different possibilities of integrating a mark because of the uses of different parameters: the scale of decomposition, size, shape and localisation of the mark, and the used color space, etc. The RGB (Red, Green, and Blue) values of each pixel of the host color image as well as the color key image are converted to HSV (Hue, Saturation, and Value) values. Then the orthogonal D4 Wavelet transform is applied in each plate of host image and key image. Now insert the key component into appropriate blocks of host image's different plates. The experimental results show the effectiveness of our algorithm.
\end{abstract}

\section{KEYWORDS:}

Digital watermarks, D4wavelet transform, color space, human visual system.

\section{INTRODUCTION}

Nowadays our life is becoming more and more permeated with Internet or widely-used communication systems and the technology allows an easy access to an almost unlimited amount of information. On the other hand with the increasing use of internet and effortless copying, tempering and distribution of digital data, copyright protection for multimedia data has an important issue. Digital watermarking emerged as a tool for protecting the multimedia data from copyright infringement. Before distributing the data, the owner embeds an invisible signature, the

DOI : 10.5121/sipij.2011.2309 
Signal \& Image Processing : An International Journal (SIPIJ) Vol.2, No.3, September 2011

watermark, into the host source (audio, text, image, or video) using a secret key. After embedding the watermark, there should be no perceptual degradation. These watermarks should not be removable by unauthorized person and should be robust against intentional and unintentional attacks.

In the literature, several techniques have been developed for watermarking. In [1], three coding methods for hiding electronic marking in document were proposed. In [2]-[5], the watermarks are applied on the spatial domain. The major disadvantage of spatial domain watermarking is that a common picture cropping operation may eliminate the watermark. Other than spatial domain watermarking, frequency domain approaches have also been proposed. In [6], a copyright code and its random sequence of locations for embedding are produced, and then superimposed on the image based on a JPEG model. In [7], the spread spectrum communication technique is also used in multimedia watermarking.

In this paper, we propose a new technique for embedding digital watermarks with visually recognizable patterns into the images. Since, in daily life, one claim a document, a creative work, and so on, by signing one's signature, stamping a personal seal or an organization's logo, such kinds of visually recognizable patterns are more intuitive for representing one's identity than a sequence of random numbers is.

First of all, we transform the RGB color space of host image as well as secrete key into corresponding HSV color space. The components are not changed, because changes in the $\boldsymbol{H}$ components could change the color balance between HSV components. The orthogonal wavelet transform [8] is applied on the each plate of the image since it gives the better results than Fourier transform. Then we distinguee the background and foreground of the host image and we embedded the secrete key into the appropriate block of background host image. This is selected by appropriate edge detector.

\section{ORGANIZATION OF PAPER:}

The paper is organized as follows: In section 2 we briefly discuss the Wavelet transform. In section 3 the general watermarking algorithm is described. In section 4 we propose an algorithm for watermarking and its process flow. Some experimental results are shown in section 5 along with few remarks. In section 6 some conclusions are drawn.

\section{WAVELETS TRANSFORM}

Wavelets transform is an efficient tool to represent an image. It allows multi resolution analysis of an image. The aim of this transform is to extract relevant information from an image [9]. Wavelet transform has received considerable attention in the field of image processing due to its ability in adapting to human visual characteristics mentioned in [10]. It is most powerful and widely used tool in the field of image processing. It divides the signal into number of segments; each corresponds to a different frequency band. The continuous wavelet transform of a one dimension signal $\mathrm{x}(\mathrm{t})$ is given by 


$$
\mathrm{W}_{\mathrm{f}}(\mathrm{a}, \mathrm{b})=\frac{1}{\sqrt{|\mathrm{a}|}} \int_{-\alpha}^{\alpha} x(t) \psi *\left(\frac{\mathrm{t}-\mathrm{b}}{\mathrm{a}}\right) d t
$$

The continuous wavelet transform is a function of two variables $\boldsymbol{a}$ and $\boldsymbol{b}$. Here $\boldsymbol{a}$ is scaling parameter and $\boldsymbol{b}$ is a shift parameter. $\Psi(\mathrm{x})$ is the mother wavelet or the basis function and it is used as a prototype for generating all the basis functions. The transformation parameter or the shift parameter $\boldsymbol{b}$ gives the time information in the wavelet transformation. It indicates the location of the window as it is shifted through the signal. The scale parameter a gives the frequency information in the wavelet transforms. A low scale corresponds to wavelets of smaller width, which gives the detail information in the signal. A high scale corresponds to the wavelets of larger width which gives the global view of the signal. The IWT is given by

$$
\begin{aligned}
& \mathrm{X}(\mathrm{t})=\frac{1}{c_{\psi}} \int_{-\alpha}^{\alpha} \int_{-\infty} \mathrm{W}_{\mathrm{f}}(a, b) \psi_{a, b}(t) d b \frac{d a}{a^{2}}, \\
& C_{\Psi}=\int_{-\infty}^{\infty}|\Psi(w)|^{2} \frac{d w}{w}<\infty
\end{aligned}
$$

The wavelet transform of a signal using the CWT is obtained by changing the scale of the analysis of the window, shifting the window in time, multiplying the signal \& integrating the result over all time. According to the orthogonal wavelet transform, the $S$ values are decomposed by the following equation

$$
\mathrm{F}(\mathrm{x}, \mathrm{y})=\sum_{\mathrm{j}=0}^{\mathrm{n}-1} \mathrm{~A}_{\mathrm{j}} \phi_{j n}(\mathrm{x}, \mathrm{y})+\sum_{\mathrm{j}=0}^{\mathrm{n}-1} \sum_{k=0}^{n} \boldsymbol{D}_{j k} \boldsymbol{\psi}_{j k}(\mathrm{x}, \mathrm{y})
$$

Here $\phi$ is the scale function and $\Psi$ is the wavelet transform. The former component of the decomposition is the approximate components and the latter one is the detail components. $A_{j}$ are the approximate and $\mathrm{D}_{\mathrm{jk}}$ are the detail components. As the transformation is an orthogonal transformation, each $A_{j}$ is in the range $[0,255]$.

The image is reconstructed by using the inverse Wavelet transformation as indicated by the equation:

$$
F^{\prime}(x, y)=\sum_{j=0}^{n-1} A^{\prime} \phi_{j n}(x, y)+\sum_{j=0}^{n-1} \sum_{k=0}^{n} D_{j k} \psi_{j k}(x, y)
$$

\section{GENERAL METHOD OF WATERMARKING}

Abstractly, a watermarking schema is six-tuple (X, W, K, G, E, D) where [11]

1. X represents the set of original or host images.

2. $\mathrm{W}$ is the set of all watermarks $\mathrm{w}$ such that $\exists \mathrm{x} \in \mathrm{X}, \mathrm{k} \in \mathrm{K}, \mathrm{w}=\mathrm{G}(\mathrm{x}, \mathrm{k})$.

3. $\mathrm{K}$ is the set of watermark key.

4. $\mathrm{G}$ be the algorithm that generates $\mathrm{W}$ using $\mathrm{K}$ and

$$
\mathrm{X}: \mathrm{G}: \mathrm{X} \times \mathrm{K} \rightarrow \mathrm{W}, \mathrm{w}=\mathrm{G}(\mathrm{x}, \mathrm{k}) \text {. }
$$


Signal \& Image Processing : An International Journal (SIPIJ) Vol.2, No.3, September 2011

5. E denotes the encoding algorithm that embeds a watermark $\mathrm{w}$ in an image $\mathrm{x}$ with some strength $\alpha$ :

$$
E: X \times W \times \mathfrak{R} \rightarrow X, x_{w}=E(x, w, \alpha)
$$

6. $\mathrm{D}$ is the decoding algorithm that detects whether a watermarking $\mathrm{w}$ is present in an image $\mathrm{x}$ :

$$
\begin{aligned}
\mathrm{D}: \mathrm{X} \times \mathrm{W} \rightarrow\{0,1\}, \mathrm{D}(\mathrm{x}, \mathrm{w}) & =1 \text { if } \mathrm{w} \text { exists in } \mathrm{x} \\
& =0 \text { otherwise }
\end{aligned}
$$

\section{PROPOSED METHOD AND ITS PROCESS FLOW}

The proposed watermarking algorithm is described as follows:

Step1: transform the RGB color space to HSV color space of host image as well as key image.

Step2: select the proper blocks for inserting key component using suitable edge detection key technique in such way that $\mathrm{H}$ block of host maps into $\mathrm{S}$ block of key image, $\mathrm{V}$ block of host image maps into $\mathrm{H}$ block of key image and $\mathrm{S}$ block of host image into $\mathrm{V}$ block of key image.

Step4: Let $\mathrm{T}$ be the transformation of H,S and V component of host and key images, compute $\mathrm{T}(\mathrm{x})$ to get transform coefficient $\mathrm{h}_{0} \quad \mathrm{~h}_{1}, \mathrm{~h}_{2}$ and $\mathrm{h}_{3}$ such that $h_{0}=\frac{1+\sqrt{3}}{\sqrt[4]{2}}, h_{1}=\frac{3+\sqrt{3}}{\sqrt[4]{2}}, h_{2}=\frac{3-\sqrt{3}}{\sqrt[4]{2}}$ and $h_{3}=\frac{1-\sqrt{3}}{\sqrt[4]{2}}$

Each step of the wavelet transform applies the scaling function to the data input. If the original data set has $\mathrm{N}$ values, the scaling function will be applied in the wavelet transform step to calculate N/2 smoothed values. In the ordered wavelet transform the smoothed values are stored in the lower half of the $\mathrm{N}$ element input vector. The wavelet function coefficient values are: $\mathrm{g} 0=$ $\mathrm{h} 3, \mathrm{~g} 1=-\mathrm{h} 2, \mathrm{~g} 2=\mathrm{h} 1$ and $\mathrm{g} 3=-\mathrm{h} 0$. Each step of the wavelet transform, applies the wavelet function to the input data. If the original data set has $\mathrm{N}$ values, the wavelet function will be applied to calculate N/2 differences (reflecting change in the data). In the ordered wavelet transform the wavelet values are stored in the upper half of $\mathrm{N}$ element input vector. The scaling and wavelet functions are calculated by taking the inner product of the coefficients and four data values. The equations are shown below. The Daubechies D4 scaling function is

$$
\begin{aligned}
& a_{i}=h_{0} s_{2 i}+h_{1} s_{2 i+1}+h_{2} s_{2 i+2}+h_{3} s_{2 i+3} \\
& a[i]=h_{0} s[2 i]+h_{1} s[2 i+1]+h_{2} s[2 i+2]+h_{3} s[2 i+3]
\end{aligned}
$$

Daubechies D4 wavelet function is

$$
\begin{aligned}
& c_{i}=g_{0} s_{2 i}+g_{1} s_{2 i+1}+g_{2} s_{2 i+2}+g_{3} s_{2 i+3} \\
& c[i]=g_{0} s[2 i]+g_{1} s[2 i+1]+g_{2} s[2 i+2]+g_{3} s[2 i+3]
\end{aligned}
$$


Signal \& Image Processing : An International Journal (SIPIJ) Vol.2, No.3, September 2011

Each iteration in the wavelet transform step calculates a scaling function value and a wavelet function value. The index $\mathrm{i}$ is incremented by two with each iteration, and new scaling and wavelet function values are calculated. This pattern is discussed on the section 3 .

Step3: If the blocks satisfy the threshold value, then insert the corresponding key component into selected blocks randomly.

Step6: output $\mathrm{x}_{\mathrm{w}}=T^{-1}\left(h^{\prime}{ }_{1}, h^{\prime}{ }_{2} \ldots \ldots \ldots . . . . h^{\prime}{ }_{n}\right)$

Step7: Now modified H component, modified S and modified V components are converted to RGB color space of host image.

Step8: show the watermarked image.

Block diagram of encoding technique is as follows:

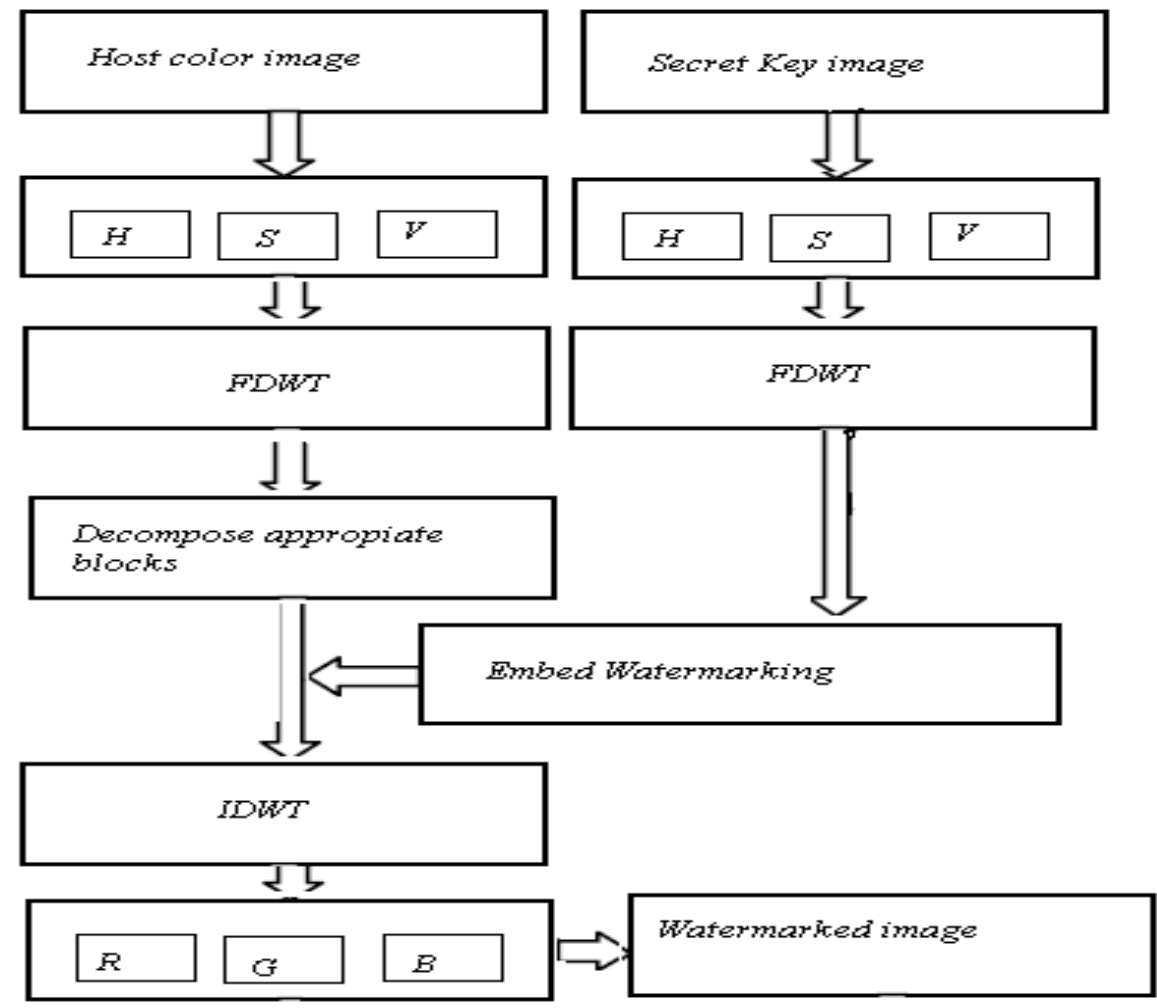

Figure: 1(Process flow of encoding technique)

The key extraction from watermarked image algorithm is described as follows:

Step1: convert the RGB color space of watermarked image to HSV color space of watermarked image.

Step2: Compute $T\left(x_{w}\right)$ to get the transform coefficients $\hat{\mathrm{v}_{1}}, \hat{\mathrm{V}}_{2} \ldots \ldots \ldots . . \mathrm{V}_{\mathrm{n}}$ 
Step3: Extract the watermarked w from the transform coefficient $\hat{v}_{1}, \hat{v}_{2} \ldots \ldots \ldots . . \hat{v}_{n}$.

Step4: Compute $\mathrm{C}\left(\mathrm{w}, \mathrm{w}^{\prime}\right)>\mathrm{t}$ where $\mathrm{t}$ be the detection threshold.

$C\left(w, w^{\prime}\right)=1-\sum_{i=1}^{m n} w_{i} \oplus w^{\prime}$ i Such that

$C\left(w, w^{\prime}\right)=1$ if $w$ exist in $x$

0 elsewhere.

Step6: now extracted H, S \& V components are converted to RGB color space on each block.

Step7: show the key.

Block diagram of decoding technique is as follows:

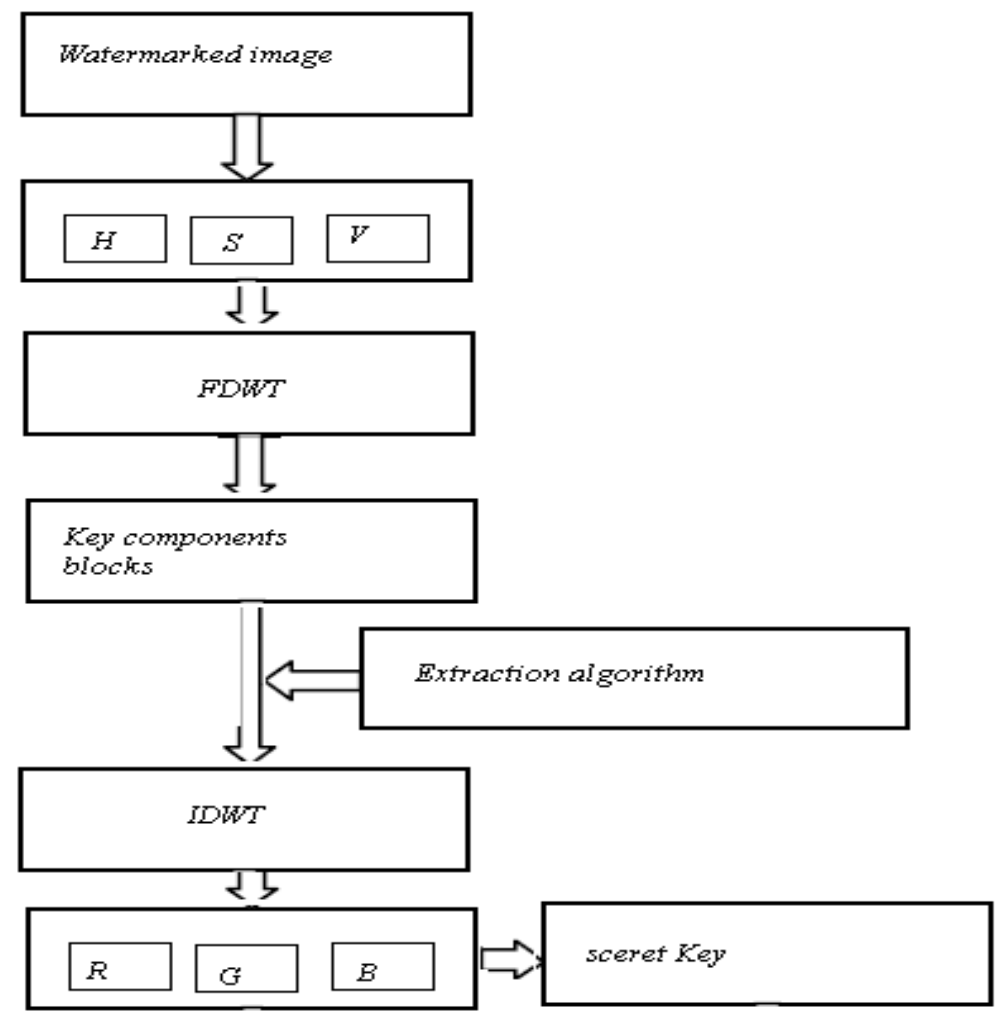

Figure:2(Process flow of decoding technique) 
Signal \& Image Processing : An International Journal (SIPIJ) Vol.2, No.3, September 2011

\section{EXPERIMENTAL RESULT}

We present a novel algorithm for color image watermarking, which consists of orthogonal wavelet transform of HSV color space. We performed fidelity tests to analyze the unobtrusiveness of the watermarks after watermark embedding, whether perceptual distortion occurred to the host images or not, i.e., why we give the few examples, which shows the effectiveness of our proposed method.

We also tested the robustness against standard noise attacks to the watermarked images which is obtained by PSNRs [12] between host image and watermarked image under standard noise degradations, which is shown in Table 1 and table 2. In this paper all experiments are done in Matlab 7.1 Version.

The source image set $\mathrm{X}$ is given as follows.

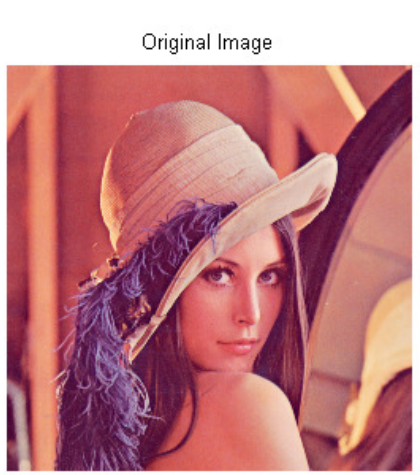

Image: 1

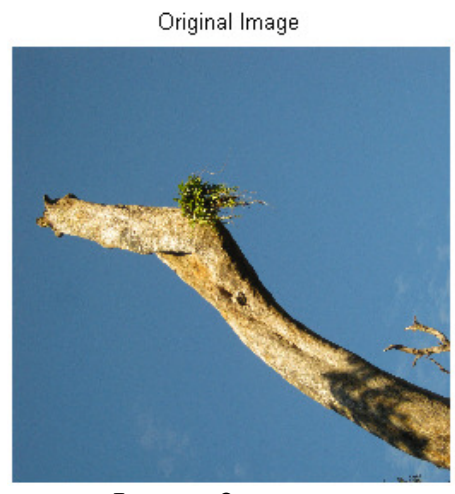

Image: 2

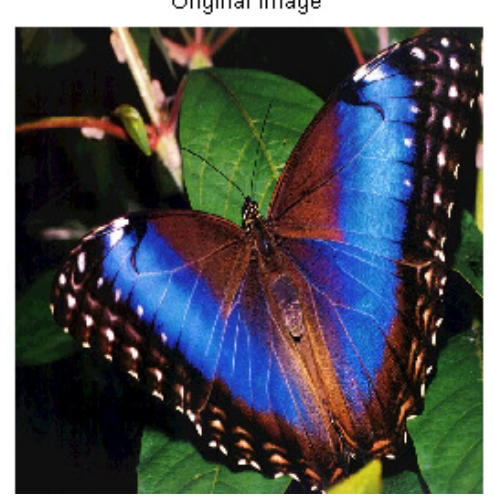

Image: 4
Original Image

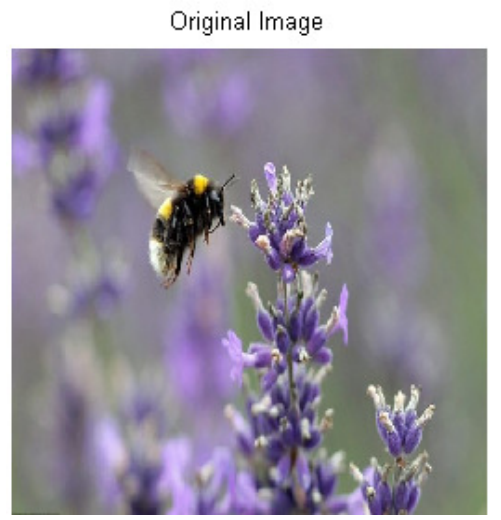

Image: 5

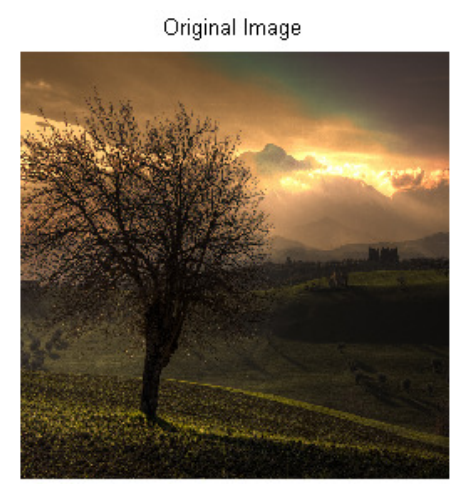

Image: 3

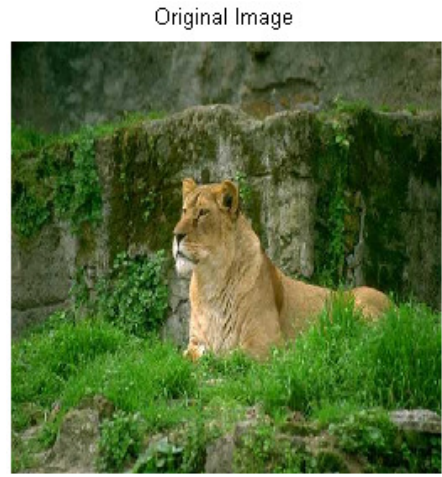

Image: 6 
Signal \& Image Processing : An International Journal (SIPIJ) Vol.2, No.3, September 2011

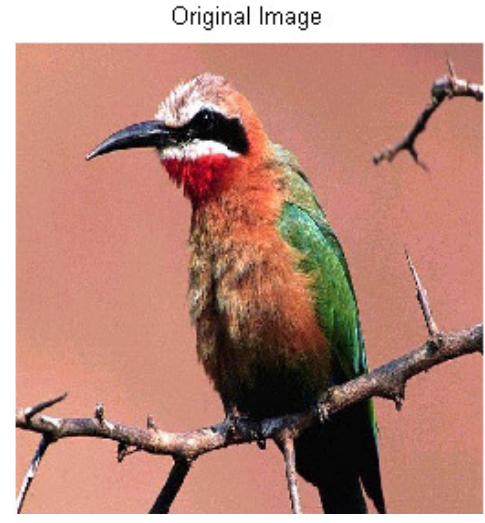

Image: 7

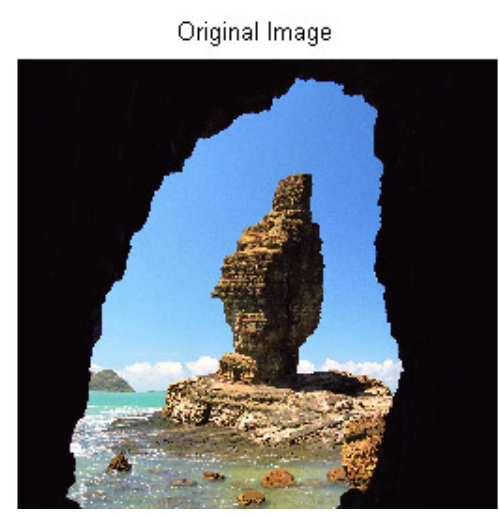

Image: 8

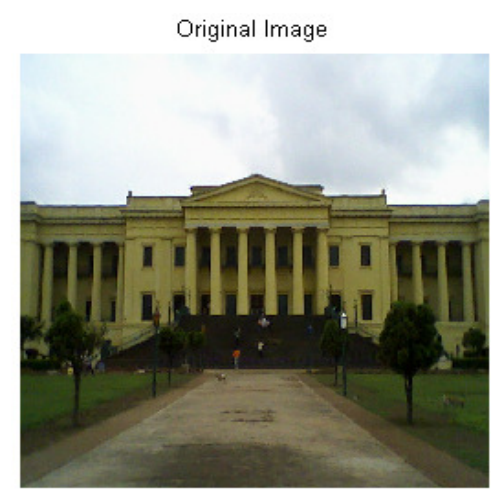

Image: 9

The secret key set $\mathrm{K}$ is given bellow:
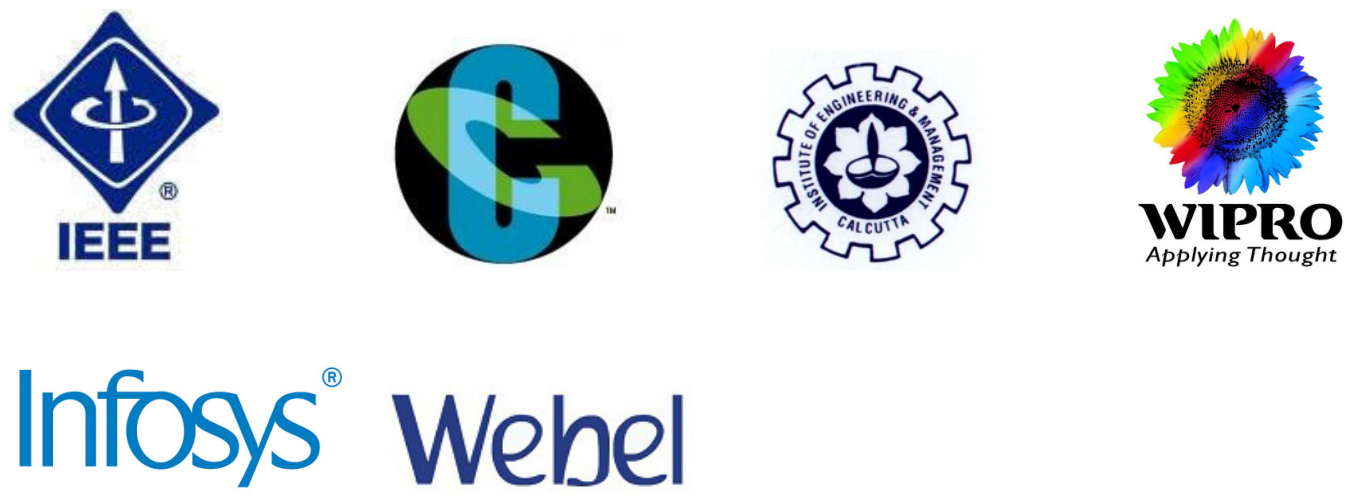

The watermark image set $\mathrm{W}$ is given by

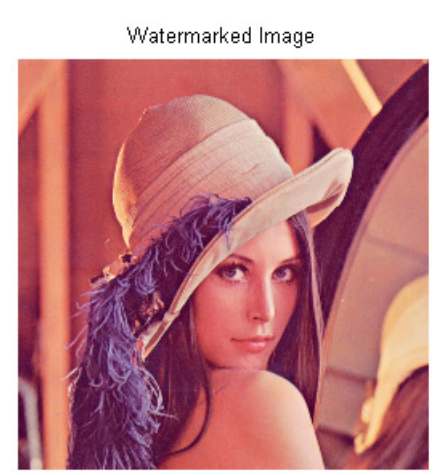

Image: 1

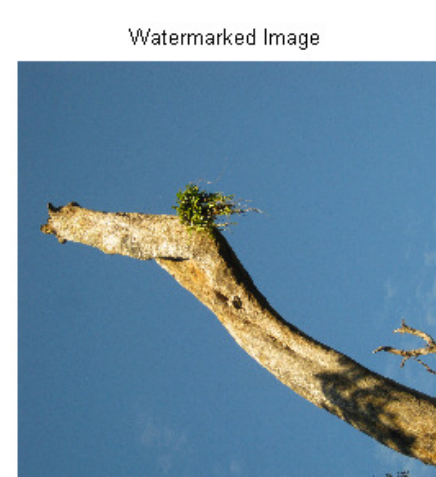

Image:2

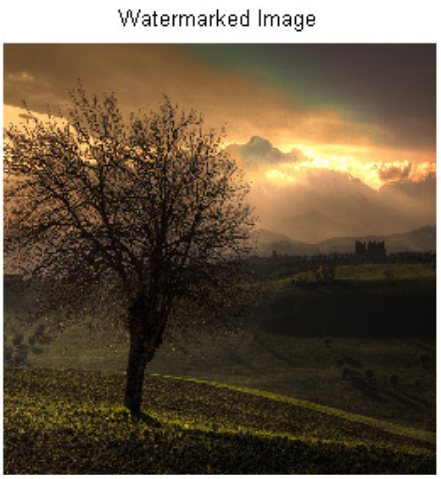

Image:3 
Signal \& Image Processing : An International Journal (SIPIJ) Vol.2, No.3, September 2011

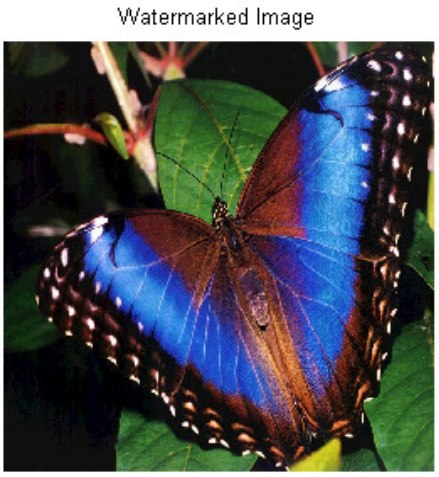

Image:4

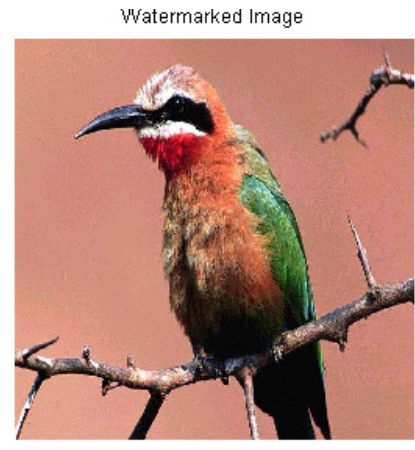

Image:7

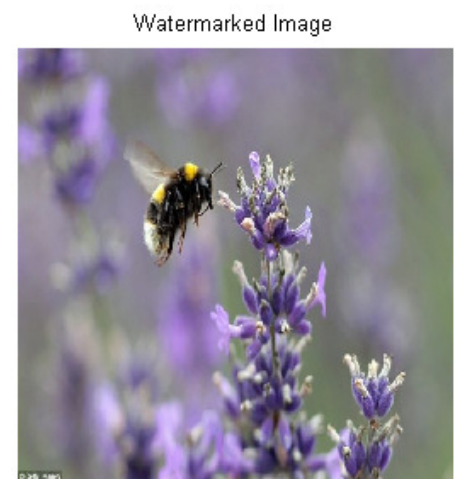

Image:5

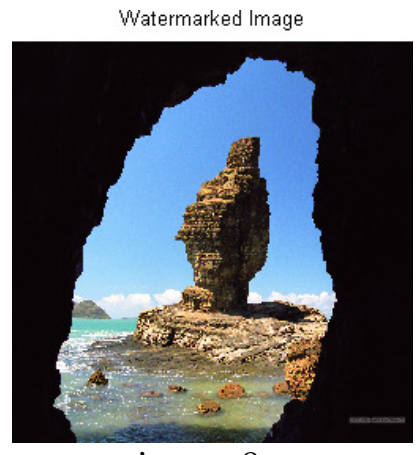

image: 8

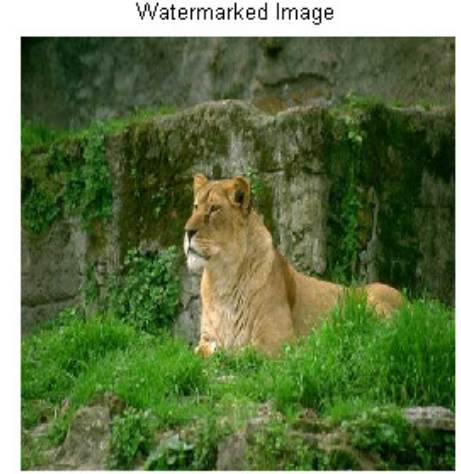

Image:6

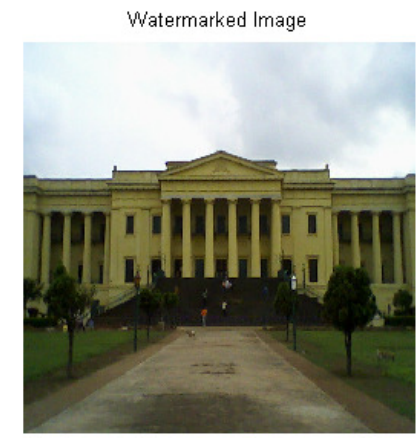

image:9

The extracted secret key set $\mathrm{K}$ from watermark image set $\mathrm{W}$ is given as follows:

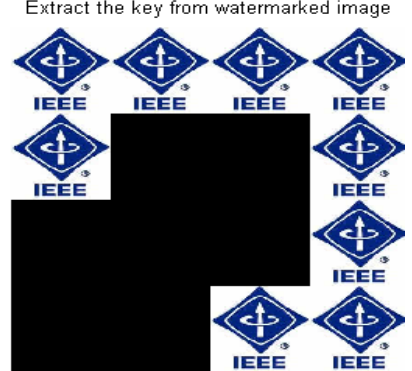

Image: 1

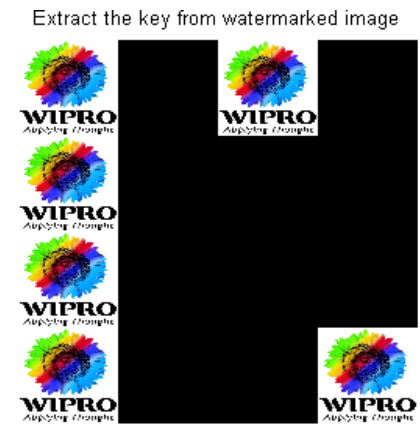

Image:4

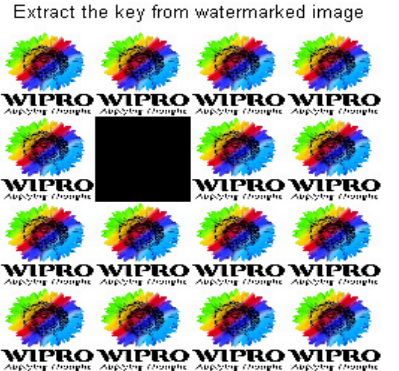

Image: 2

Extract the key from watermarked image

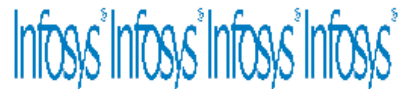

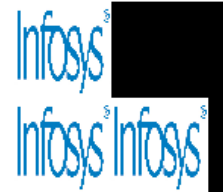

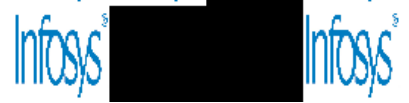

Image:5

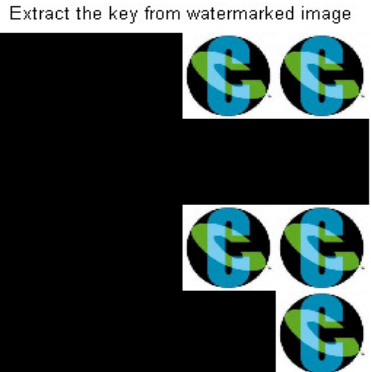

Image:3

Extract the key from watermarked image

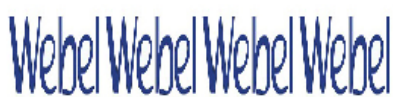
Whed Weed Whed Weed

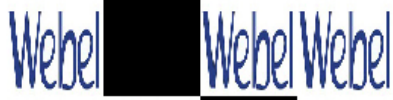
Weot Wend Whed

Image:6 
Signal \& Image Processing : An International Journal (SIPIJ) Vol.2, No.3, September 2011

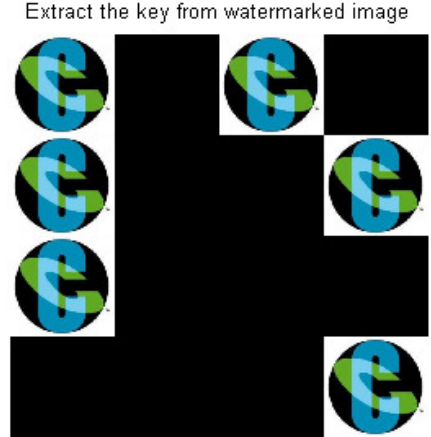

Image:7

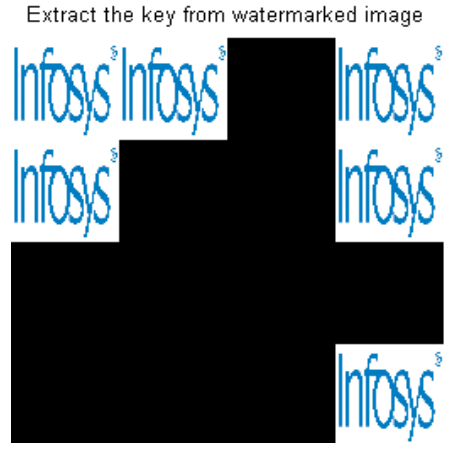

Image: 8
Extract the key from watermarked image

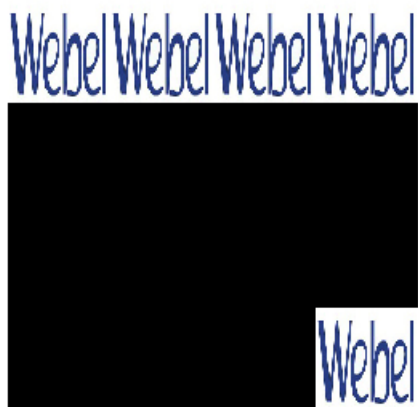

Image:9

\begin{tabular}{|l|l|l|l|l|}
\hline S1 no. & $\begin{array}{l}\text { Image } \\
\text { name }\end{array}$ & Key name & $\begin{array}{l}\text { No of key in } \\
\text { watermarked image \& } \\
\text { it's possitions }\end{array}$ & PSNR \\
\hline 1 & Image: 1 & ieee logo & $9(1,2,3,4,5,8,11,15,16)$ & 51.3038 \\
\hline 2 & Image: 2 & wipro logo & $\begin{array}{l}15(1,2,3,4,5,7,8,9,10,1 \\
1,12,13,14,15,16)\end{array}$ & 57.1478 \\
\hline 3 & Image: 3 & cts logo & $5(3,4,11,12,16)$ & 57.8626 \\
\hline 4 & Image: 4 & wipro logo & $6(1,3,5,9,13,16)$ & 61.5340 \\
\hline 5 & Image:5 & $\begin{array}{l}\text { infosys } \\
\text { logo }\end{array}$ & $\begin{array}{l}11(1,2,3,4,5,8,9,10,12, \\
13,16)\end{array}$ & 53.8647 \\
\hline 6 & Image:6 & webel logo & $\begin{array}{l}14(1,2,3,4,5,6,7,8,9,11 \\
, 12,13,14,16)\end{array}$ & 58.7990 \\
\hline 7 & Image: 7 & cts logo & $6(1,3,5,8,9,16)$ & 51.5364 \\
\hline 8 & Image: 8 & infosys & $6(1,2,4,5,8,16)$ & 59.6433 \\
\hline 9 & Image: 9 & webel logo & $5(1,2,3,4,16)$ & 54.4222 \\
\hline
\end{tabular}

Table:1(various position of key in watermarked image)

\begin{tabular}{|l|l|l|l|l|}
\hline $\begin{array}{l}\text { Sl } \\
\text { no. }\end{array}$ & $\begin{array}{l}\text { Image } \\
\text { name }\end{array}$ & $\begin{array}{l}\text { PSNR } \\
\text { after Salt } \\
\text { \& pepper } \\
\text { attack }\end{array}$ & $\begin{array}{l}\text { PSNR after } \\
\text { Gaussian } \\
\text { attack }\end{array}$ & $\begin{array}{l}\text { PSNR } \\
\text { after } \\
\text { compress } \\
\text { ion }\end{array}$ \\
\hline 1 & Image: 1 & 51.1744 & 51.2100 & 51.3038 \\
\hline 2 & Image:2 & 56.9560 & 57.1236 & 57.1478 \\
\hline 3 & Image:3 & 57.5971 & 57.8382 & 57.8626 \\
\hline 4 & Image: 4 & 60.9982 & 61.2032 & 61.5340 \\
\hline 5 & Image:5 & 53.7788 & 53.7611 & 53.8647 \\
\hline 6 & Image: 6 & 58.5117 & 58.7126 & 58.7990 \\
\hline 7 & Image:7 & 51.4622 & 51.3570 & 51.5364 \\
\hline 8 & Image: 8 & 59.2868 & 59.3065 & 59.6433 \\
\hline 9 & Image: 9 & 54.2168 & 54.2727 & 54.4222 \\
\hline
\end{tabular}

Table:2(PSNR calculation after various attacks) 
Signal \& Image Processing : An International Journal (SIPIJ) Vol.2, No.3, September 2011

The experimental results shows that, there is no perceptual distortion in original image and watermarked image, which means that scheme has satisfied the criteria that an efficient watermark should be unobtrusive, discreet and easily extracted.

\section{CONCLUSION}

This paper presented a novel algorithm, which is based on color space and wavelet transform. The key is inserting in the appropriate plates of the images depending upon the nature of the plates. Compared with other techniques, our technique has higher capabilities and lower computational cost under the same robustness. It can be extended to multimedia watermarking. The performance of the watermarking is evaluated in common image processing attacks such as additive noise, filtering, histogram equalization, JEPG compression, scaling and rotation. Experimental result demonstrates that watermark is robust against those attacks.

\section{REFERENCES}

[1] J. T. Brassil, S. Low, N. F. Maxemchuk, and L. O'Gorman, "Electronic marking and identification techniques to discourage document copying," IEEE J. Select. Areas Commum., vol. 13, pp. 14951504, Oct. 1995.

[2] I. Pitas and T. H. Kaskalis, "Applying signatures on digital images," in Proc. IEEE Nonlinear Signal and Image Processing, June 1995, pp. 460-463.

[3] O. Bruyndonckx, J. J. Quisquater, and B. Macq, "Spatial method for copyright labeling of digital images," in Proc. IEEE Nonlinear Signal and Image Processing, June 1995, pp. 456-459.

[4] S. Walton, "Image authentication for a slippery new age," Dr. Dobb's J., pp. 18-26, Apr. 1995.

[5] W. Bender, D. Gruhl, and N. Morimoto, "Techniques for data hiding," Proc. SPIE, vol. 2420, p. 40, Feb. 1995

[6] E. Koch and J. Zhao, "Toward robust and hidden image copyright labeling," in Proc. IEEE Nonlinear Signal and Image Processing, June 1995, pp. 452-455.

[7] I. J. Cox, J. Kilian, T. Leighton, and T. Shammoon, "Secure spread spectrum watermarking for multimedia,” Tech. Rep. 95-10, NEC Res. Inst., Princeton, NJ, 1995.

[8] M. J. Shensa, "Discrete wavelate transform: wedding the trous Mallat algorithms", IEEE Trans. On signal processing Vol. 40, No. 10, pp, 2464-2482.

[9] C.C Yang \& J. J. Rodrgues, "Efficient luminance and saturation processing technique for bypass color coordinate transformation", Proc. IEEE Conf. on systems, Man and Cybernetics, Bogota, Columbia, 1995, 56-67

[10] B.A. Tomas and R.N.Strickland, "Color image enhancement using spatially adaptive saturation feedback”, IEEE Ind., Conf. on Image Processing, Vol. 3, pp, 30-33, 1997

[11] G.Voyatzis and I.Pitas,"the use of watermarks in the protection of multimedia products", proceedings of the IEEE, vol. 87,no. 7,July 1999, pp.1197-1207. 
Signal \& Image Processing : An International Journal (SIPIJ) Vol.2, No.3, September 2011

[12] K.Hameed, A.Mumtaz and S.A.M.Gilani "Digital image watermarking in the wavelate transform domain", World Academy of Science and Technology,13 2006

\section{Authors}

Kartik Sau: Associate Professor, Department of Computer Science \& Engineering, Budge Budge Institute of technology. He completed his B.Sc. in mathematics from RK Mission Vidyamandira, University of Calcutta. And M. Sc. in the same subject from Indian Institute of Technology, Kharagpur. M. Tech in Computer Science from Indian School of Mines, Dhanbad. Currently he is Head of the Department of BBIT and member of Govt. body of the same Institute; He has presented many papers in International and National journals and Conference. His area of interest includes Digital Image processing, Artificial Intelligence, Pattern Recognition, Soft computing, etc. He has more than eight years teaching and research experience in his area of interest.

Dr. Amitabha Chanda: Visiting Professor; Department of Computer Science, UCSTA; Calcutta University. He completed his B.E in Chemical Engineering (Jadavpur), M.A. in Pure Mathematics and $\mathrm{Ph} . \mathrm{D}$ in Mathematics from university of Calcutta. He was a faculty member of Indian Statistical Institute (ISI), Kolkata. Now he is also guest faculty member of ISI, Kolkata; Department of Computer Science, Rajabazar Science College, Kolkata. His area of interest includes Digital Image processing, Pattern Recognition Fuzzy logic, Genetic Algorithms, Computer Graphics, Control system Turbulence, Fractal, multifractals, Clifford Algebra, Nonlinear dynamics. He has more than fifty years teaching and research experience in his area of interest. He has presented more than 100 papers in International and National journals and Conference. Dr. Chanda is an Associate member of American Mathematical Society.

Milan Pal: He received his B. Tech degree in Computer Science \& Engineering from Bankura Unnayani Institute of Engineering, WBUT, India. He completed his M.Tech in Computer Science \& Engineering from Institute of Engineering \& Management, Salt Lake Kolkata, India. His area of interest includes Digital Image Processing, Pattern Recognition Fuzzy logic, Genetic Algorithms and DBMS. 